\title{
Study of Interphase in Glass Fiber-Reinforced Poly(Butylene Terephthalate) Composites
}

\author{
A. BERGERET*, M. P. BOZEC, J.-C. QUANTIN, and A. CRESPY \\ Ecole des Mines d'Alès-Centre des Matériaux de Grande Diffusion \\ 6 avenue de Clavières-30319 Alès Cedex-France \\ and \\ J.-P. GASCA and M. ARPIN \\ Saint Gobain-Vetrotex International \\ 767 quai des Allobroges-BP 929-73009 Chambéry Cedex-France
}

\begin{abstract}
It is well known that application of a coupling agent to a glass fiber surface will improve fiber/matrix adhesion in composites. However, on commercial glass fibers, the coupling agent forms only a small fraction of the coating, the larger part being a mixture of processing aids whose contribution to composite properties is not well defined. The interfacial region of the composite will therefore be affected by the coating composition and also by the chemical reactions involved in the vicinity of the fiber and inside the surrounding matrix. The main feature of this study consists in dividing the interface region into two separate regions: the fiber/sizing interphase and the sizing/matrix interphase. A wide range of techniques was used, including mechanical and thermomechanical tests, infrared spectroscopy, gel permeation chromatography, carboxyl end group titrations, extraction rate measurements, and viscosity analysis. Experiments were performed on poly(butylene terephthalate) composites and results indicate that the adhesion improvement is due to the presence of a short chain coupling agent and of a polyfunctional additive, which may react both with the coupling agent and the matrix. According to the nature of this additive, it may be possible to soften the interphase and then to increase the composite impact strength.
\end{abstract}

\section{INTRODUCTION}

$\mathrm{M}$ echanical properties of composite materials such as polybutylene terephthalate (PBT/glass fibers) are closely linked both to the intrinsic characteristics of the matrix and of the fiber, and to the nature of the fiber/matrix interface. The latter should allow an efficient transfer of mechanical stresses within the composite material. The classical concept of an interface without any width and corresponding to chemical interactions between the polymeric matrix and the glass fiber has been updated by the concept of an interphase with a given width and located in the vicinity of the glass surface. The interphase has a chemical structure as well as mechanical properties (1) different from the core of the matrix. Until now, normalized

*Corresponding author: Email: Anne.Bergeret@ema.fr methods have not existed for measuring the quality of the fiber/matrix interphase. Nevertheless, many investigations were carried out in recent decades to develop and to improve techniques for the characterization of interfacial structures based on physico-chemical studies, on micromechanical measurements and on viscoelastic analysis.

The aim of physico-chemical studies is to identify the structure of the coupling agent on the glass fiber surface and of the coupling agent in presence of a polymeric resin. The most common methods available for probing the interphase are spectroscopic methods (FTIR spectroscopy, Raman spectroscopy, Auger electron spectroscopy or AES, secondary ion mass spectrometry or SIMS, sputtered neutral mass spectrometry or SNMS), differential scanning calorimetry (DSC), solid state $\mathrm{C}^{13}$-NMR and gel permeation chromatography (GPC). Culler et al. (2) used FTIR spectroscopy to study the drying under air of an aminosilane/epoxy resin 
blend. They observed that above $120^{\circ} \mathrm{C}$, amine groups of the silane are oxydated in imine groups and therefore no longer reacted with epoxy functions of the matrix. Hoh et al. (3) used DSC, FTIR and $\mathrm{C}^{13}$-NMR to gain information about the silane/epoxy resin interphase. Penetration of epoxy into the hydrolyzed silane has been shown so that the possible formation of entanglements may increase the rigidity and decrease the degree of phase separation of the two previous components. By SNMS techniques, Gentle et al. (4) found that interdiffusion of the coupling agent with the polymer was maximized when their solubility parameters were matched. FTIR was utilized by Liao (5) to characterize the interfacial bonding in glass fiber/epoxy composites as a function of the $\mathrm{pH}$ of the silane solution and of the temperature. A natural $\mathrm{pH}$ should induce the maximum interfacial bonding as the temperature has no effect. Through Fourier transform infrared diffuse reflectance spectroscopy (DRIFT) and GPC measurements, Nishiyama (6) gave evidence that adsorption mechanisms of silane on a silica surface were related to the initial amount of silane.

Micromechanical tests, such as monofilament pullout tests, micro-indentation tests, and fragmentation tests, have been used to investigate the interfacial bond strength in composite systems. In some cases, data were correlated to contact angle measurements. A pull-out test on a glass monofilament/epoxy resin composite was performed on by Koenig et al. (7) and gave evidence of the existence of a critical amount of silane coupling agent around $0.5 \%$ that induced a maximum interfacial shear stress. This result was also obtained by Berger et al. (8) and was correlated to the wetting characteristics of the glass by the resin. The dependence of the magnitude of the interfacial parameters for a glass fiber-reinforced polypropylene on the thickness of the applied silane layer was investigated through pull-out experiments (9). The results indicated that the maximum interfacial shear strength is obtained at a critical thickness of about $3 \mu \mathrm{m}$ and that interfacial frictional stress decreased with increased thickness of the silane coating. Through contact angle measurements, Thomason (10) showed that contact angles values decrease as the glass surface becomes better coated and more chemically homogeneous. Nevertheless, as micromechanical tests allow researchers to gain information on interfaces, sample preparation for this kind of experiment is tricky so that no absolute values for adhesion could be obtained and only comparative analysis could be performed. Moreover, some difficulties should exist when extrapolating results to the global composite.

Many investigations have been carried out to characterize fiber/matrix adhesion from dynamic mechanical analysis. For fiber-reinforced polyester composites, Chua (11) proposed a comparison between two types of organosilanes (a reactive organosilane towards the polyester resin and a non-reactive organosilane). This author showed that the magnitude of the $\alpha$ relaxation, which corresponds to the maximum of tan $\delta$ (identified for viscoelastic materials with the glass transition as the ratio of the dissipated energy, i.e., due to molecular motion, to the stored energy), and interfacial strength are related to the reactivity of the organosilane with the polyester matrix. The presence of unreactive organic groups from the organosilane suggests the presence of unrestrained end groups and consequently low crosslinked networks in the "plasticized" interphase. Thus a high $\tan \delta$ value was observed, and this corresponds to a weak interfacial shear strength. Reactive organosilanes are capable of polymerization with the polyester matrix and thus exhibit low $\tan \delta$ values because of an improved interfacial adhesion. The influence of different surface coatings on the viscoelastic behavior of styrene-methacrylic acid copolymers reinforced by glass beads was studied by Bergeret et al. (12). Changes in molecular mobility due to an increase in the number of bonds in the interphase have induced a drop in $\tan \delta$ and a shift of the $\tan \delta$ peak towards higher temperatures. Viscoelastic characteristics of unidirectional glass/epoxide composites have been determined by Chauchard et al. (13) by submitting the sample to a three-point flexion dynamic mechanical solicitation. The presence of an aminosilane linking agent increases the rubber-like modulus and decreases the $\tan \delta$ value especially in the case of out-axis study. Some authors (10, 14-17) have observed the presence of an additional relaxation related to the interphase, which was located between the main relaxation of the matrix and the relaxation of the coating. Gauthier et al. (18) carried out experiments on glass fiber bundles coated by different sizing systems at various temperatures. The authors concluded for fibers reactive toward the matrix that the higher the temperature, the more crosslinked the coating and the more shifted the tan $\delta$ peak to higher temperature.

Many studies aimed at improving the adhesion between glass fibers and resins have been performed. Nevertheless, it seems difficult to obtain an efficient characterization of the adhesion through one particuliar technique.

Moreover, the silane coupling agent forms only a small fraction of the applied coating for commercial glass fibers. In fact this coating also contains a mixture of processing aids whose contributions to composite properties are not well defined and which includes a silane coupling agent but also sticking agents, lubricants and other additives. In contrast to the growing amount of literature available on coupling agents, very little (10) has been published on the full coating package. This is primarily due to the reluctance of the glass fiber manufacturers to reveal the composition of these coatings and the details of their application to the fibers. Nevertheless, it is well known that the main role of sticking agents is three-fold: (i) to protect the glass fibers during the fiber processing, (ii) to stick together the elementary filaments to form a glass fiber and (iii) to create chemical and/or physical links between the coupling agent and the polymer matrix. 
This paper, which describes a part of a larger study (19), will propose a new and more complete approach for the characterization of the interphase in the case of commercial coatings of glass fibers incorporated in a PBT matrix.

\section{METHODOLOGY}

The originality of this study lies in its methodology, which is different from the classical methodologies discussed in the Introduction and based either on microscopic approaches to characterize the coating systems, which are most of the time reduced to the single silane coupling agent, or on macroscopic approaches to evaluate the interphase characteristics through mechanical simulations. Based on the fact that composite materials are constituted of three components, i.e., the glass fiber, the sizing, and the matrix, we propose in this paper to study on the one hand the fiber/sizing interphase and on the other hand the sizing/matrix interphase.

As concerns the fiber/sizing interphase, the present work consists in reconstructing the interfacial region at a macroscopic scale by using films obtained after the drying of the sizing solutions. Therefore a two-step study is proposed: (i) determination of the main chemical reactions liable to exist between each component of the sizing formulation. Soxhlet extractions are therefore performed on these films to measure the solubilization rate and to analyze the nature of extractable and non-extractable parts of the films through FTIR and GPC experiments; (ii) applying the same extraction procedure on the surface of the treated fibers to propose a scheme of the different chemical reactions involved between the fiber surface and the components of the coating.

As concerns the sizing/matrix interphase, another two-step study is proposed: (i) the elaboration and the characterization of PBT/sizing film blends through mechanical, viscoelastic and physico-chemical measurements in order to determine chemical reactions involving the matrix and the components of the coating; (ii) the study of the whole composite to propose a chemical description of the interphase region.

\section{EXPERIMENTAL}

\section{Materials}

\section{Matrix}

Poly(butylene terephthalate) (PBT) was obtained from the DuPont de Nemours Company (Geneva, Switzerland) under the trade name Crastin ${ }^{\circledR}$. Its weight-average molar weight $\overline{M_{w}}$ determined by a light scattering method is 19,100 Daltons. The content of carboxyl end groups is about 45 equivalent $/ 10^{6} \mathrm{~g}$ and was measured by titration using Pohl's method (20).

\section{Fibers}

Two different E-glass fibers (called $F_{1}$ and $F_{2}$ ) were provided by Saint Gobain-Vetrotex International
Company (Chambéry, France) with two different "PBT-compatible" sizing systems. Corresponding sizing solutions, respectively denominated $\mathrm{E}_{1}$ and $\mathrm{E}_{2}$, are both constituted of an aminosilane coupling agent and an epoxy sticking agent (named A). A low molecular weight polyfunctional epoxy resin (named $\mathrm{B}$ ) is added to the sizing solution $\mathrm{E}_{2}$.

\section{Composites}

Poly(butylene terephthalate) composite specimens were reinforced by $15 \mathrm{wt} \%$ of glass fibers. A co-rotating twin screw extruder (Clextral BC45) was used to mix the glass fibers and the polymer matrix. The pellets of compounds were then injection molded at $265^{\circ} \mathrm{C}$ (Billion Visumat) and cooled at $60^{\circ} \mathrm{C}$ to obtain dumbbells according to ISO 527-2 type 1A standard.

\section{Films}

Sizing films (named $\mathrm{FE}_{1}$ and $\mathrm{FE}_{2}$ ) were prepared from sizing solutions after an optimized drying procedure, which should simulate the heat treatment of the fiber during the fiber process. Therefore, sizing solutions casted onto aluminum substrates were then dried through a three-step process, i.e. for $24 \mathrm{~h}$ at $75^{\circ} \mathrm{C}$ (to evaporate water) then for $7 \mathrm{~h}$ at $120^{\circ} \mathrm{C}$ (to evaporate the solvent of the epoxy sticking agent A) and finally for $2 \mathrm{~h}$ at $140^{\circ} \mathrm{C}$ (to induce the sizing crosslinking without any degradation effect).

\section{Blends}

$\mathrm{PBT} /$ sizing films (80/20 wt\%), named $\mathrm{PBT} / \mathrm{FE}_{1}$ and $\mathrm{PBT} / \mathrm{FE}_{2}$, were obtained through extrusion (Clextral $\mathrm{BC} 21$ ), then injection molded at $265^{\circ} \mathrm{C}$ (Sandretto Serie Otto A.T.), and cooled at $60^{\circ} \mathrm{C}$ to obtain dumbbells according to international ISO 527-2 type 1A standard. PBT/sticking agents (95/5 wt\%), called PBT/A and $\mathrm{PBT} / \mathrm{B}$, were also elaborated for comparative purposes. The content of sticking agents in these last blends is lower than those of PBT/sizing film blends to keep the same content of epoxy-containing components in the blends and thereby the same reactivity.

\section{Techniques}

Mechanical Properties: Tensile and Impact Tests

Ultimate data were obtained in the tensile mode on an Adamel Lhomargy DY26 testing machine. The experimental procedure and the sample dimensions were defined according to the international ISO 527 standard. Charpy impact strength was measured on unnotched samples by means of a Zwick 5102 apparatus according to the international ISO 75 standard.

\section{Dynamic Mechanical Properties}

A viscoelasticimeter (VA815 Metravib R.D.S.) was used in the tensile mode for recording the dynamic mechanical spectra versus temperature (from $-150^{\circ} \mathrm{C}$ to $+150^{\circ} \mathrm{C}$ ) at a frequency of $5 \mathrm{~Hz}$ on parallelepipedic 
samples $\left(25 \times 4 \times 2 \mathrm{~mm}^{3}\right)$ to study $\alpha$ and $\beta$ mechanical relaxations associated respectively to the glass and subglass transitions of PBT.

\section{FTIR Measurements}

Fourier Transform Infrared (FTIR) spectra were recorded from thin layers of extracted coating deposited on an ATR window (Golden-Gate ${ }^{\circledR}$ ) using a Bruker IFS66 instrument. Sixty-four scans of each sample at a resolution of $2 \mathrm{~cm}^{-1}$ were collected. A minimum of three samples was used in each measurement.

\section{Gel Permeation Chromatography Analysis}

Gel permeation chromatograms were determined with a Waters Associates instrument with five crosslinked polystyrene columns of pore sizes (Phenomenex $5 \mu \mathrm{m} 50 \AA$ A., Waters $10 \mu \mathrm{m} 0.5 \AA$, $500 \AA$, $10^{3} \AA$, $10^{4} \AA$ ). Extracted fractions of sizing films were dissolved into filtrated tetrahydrofurane $(0.5 \mathrm{wt} \%)$ and injected (1 $\mathrm{ml} / \mathrm{min})$. The detector was a refractometer, the response of which was calibrated by integrating chromatograms based on narrow molecular weight distribution polystyrene standards used as references. A minimum of three samples was used in each determination.

\section{Differential Scanning Calorimetric Measurements}

Differential scanning calorimetric measurements were performed on a DSC Setaram 92 apparatus (temperature rate of $10^{\circ} \mathrm{C} / \mathrm{min}$ from ambient to $180^{\circ} \mathrm{C}$ and $2^{\circ} \mathrm{C} /$ min from 180 to $250^{\circ} \mathrm{C}$ ). Melting temperatures and enthalpies were then determined for each blend. Variations in the melting enthalpy are correlated to variations in the crystallinity ratio.

\section{Viscosity Measurements}

Viscosities of blends were determined according to the international ISO $1628 / 1$ and ISO $1628 / 5$ standards in a dilute solution capillary viscosimeter (Ubbelohde, diameter $=0.76 \mathrm{~mm}$ ) of the dilution type (in a solvent mixture phenol/tetrachloroethane 50/50 wt\% at $25^{\circ} \mathrm{C}$ ) by extrapolation to zero concentration of specific viscosity measurements obtained at four different concentration levels (3.5 g/1, $4.2 \mathrm{~g} / 1,5.6 \mathrm{~g} / 1$ and 7.0 $\mathrm{g} / 1)$. A minimum of three measurements were performed for each solution.

\section{End Group Analysis}

Carboxyl content was determined according to Pohl's method (20), which entails a rapid dissolution of the polymer in benzyl alcohol at a high temperature $\left(204^{\circ} \mathrm{C}\right)$, then a quenching of this solution until about $170^{\circ} \mathrm{C}$, then a mixture of this solution with chloroform, and finally a titration with the aid of a phenol red indicator $(0.1 \%$ in ethanol) and sodium hydroxide $(0.01 \mathrm{~N}$ in ethanol). For these experiments it was assumed that the reactivity of carboxyl end groups is higher than that of the hydroxyl end groups towards epoxy functions, in agreement with literature (21).

\section{Extraction Conditions}

A preliminary study was performed to determine the optimal extraction conditions both for sizing films and for glass fibers. The extraction duration corresponds to the minimum time necessary to reach the maximum amount of extractable coating. Therefore, Soxhlet extractions were performed (i) for $3 \mathrm{~h}$ in cyclohexane and then $3 \mathrm{~h}$ in ethyl acetate for glass fibers and (ii) for $7 \mathrm{~h}$ in ethyl acetate for sizing films. The difference in extraction conditions between films and fibers is due the fact that (i) the amount of extractable coating in cyclohexane was negligible (below 1\%) for films and that (ii) the sizing films are thicker than the size deposited on fibers, inducing an increased extraction duration in ethyl acetate to reach the maximum amount. The amounts of extractable coating were measured by weighing sizing films and after pyrolysis for glass fibers.

\section{RESULTS AND DISCUSSION}

\section{Fiber/Sizing Interphase}

The results indicating the amounts of extractable coating are: $93.5 \pm 1.2 \mathrm{wt} \%$ for $\mathrm{FE}_{1}, 87.5 \pm 2.2 \mathrm{wt} \%$ for $\mathrm{FE}_{2}, 87.4 \pm 0.9 \mathrm{wt} \%$ for $\mathrm{F}_{1}$ and $81.9 \pm 0.9 \mathrm{wt} \%$ for $\mathrm{F}_{2}$ The amount of extractable coating is lower for the film $\mathrm{FE}_{2}$ and the fiber $\mathrm{F}_{2}$, therefore in presence of the low molecular weight polyfunctional epoxy additive B. That may indicate that the presence of this additive in the sizing formulation has an effect on the sizing crosslinking and on the amount of bound material on the glass fiber surface. It may be that the aminosilane reacts with this additive. However, more detailed knowledge is necessary before hard conclusions can be drawn from these results.

FTIR absorption spectra from non-extractable fraction of films $\mathrm{FE}_{1}$ (a) and $\mathrm{FE}_{2}$ (b) are shown in Fig. 1. For comparative purposes, the spectra of the epoxy sticking agent A (c) and of the low molecular polyfunctional epoxy additive B (d) are also shown. It can be seen that the spectra (a) and (b) are very similar. Peaks at $1100 \mathrm{~cm}^{-1}, 1020 \mathrm{~cm}^{-1}$ and $695 \mathrm{~cm}^{-1}$ indicate that the aminosilane is present in both non-extractable fractions under a polysiloxane form. As no peak located at $1507 \mathrm{~cm}^{-1}$ and $826 \mathrm{~cm}^{-1}$ on Fig. 1c and related to the $\mathrm{C}=\mathrm{C}$ function is observed on both non-extractable fractions of films, it can be assumed that no epoxy sticking agent $\mathrm{A}$ is present. Moreover, as no intense peak located at $915 \mathrm{~cm}^{-1}$ on Fig. $1 d$ and related to the epoxy is observed, it can be also assumed that no epoxy additive B is present. Nevertheless, identification of the epoxy additive B (free or linked to aminosilane) in the non-soluble part of the film $\mathrm{FE}_{2}$ requires a more detailed analysis. Some discrepancies in peak intensities at $1635 \mathrm{~cm}^{-1}$ and 1560 $\mathrm{cm}^{-1}$ and an extra peak at $1400 \mathrm{~cm}^{-1}$ can be observed 


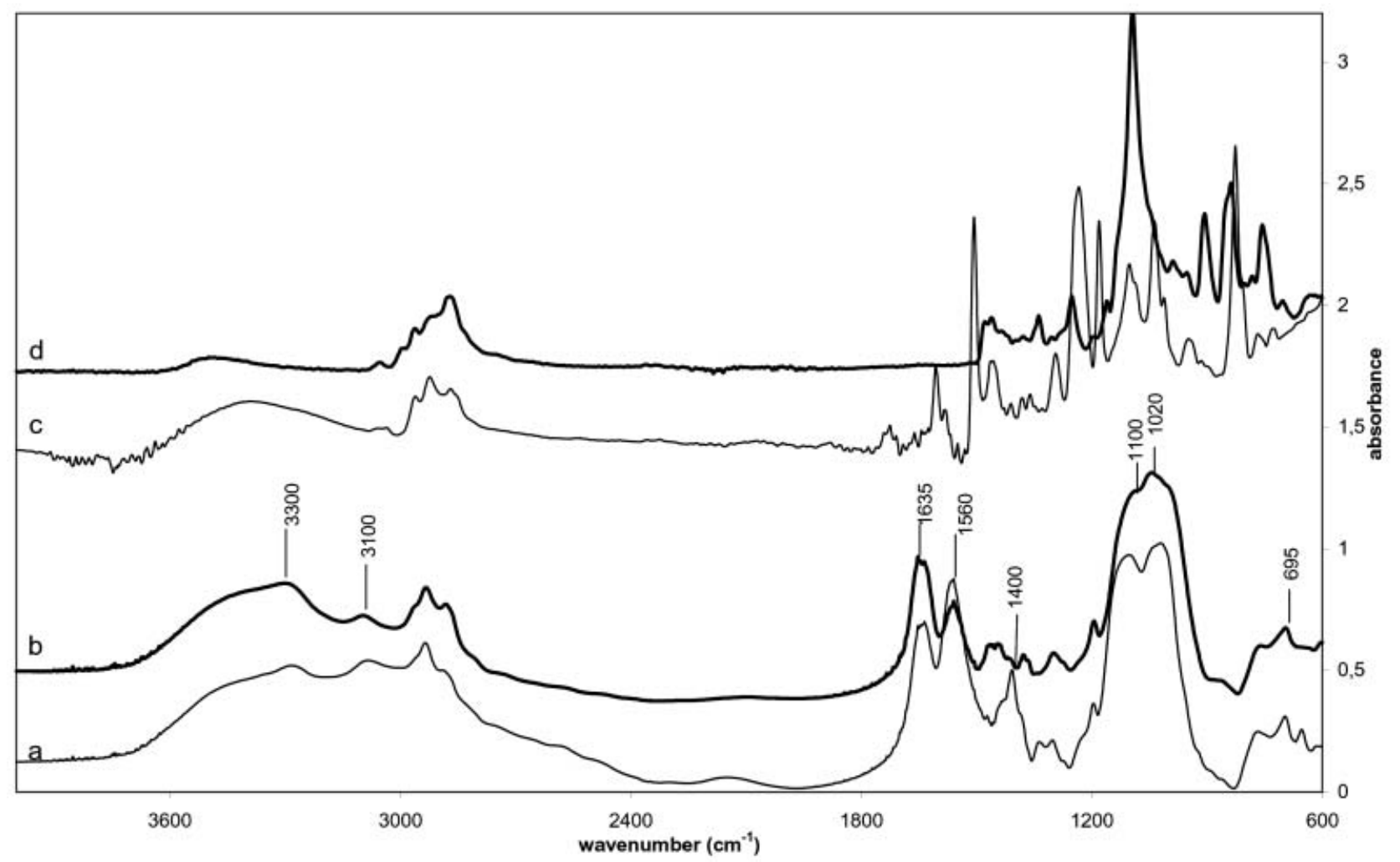

Fig. 1. FTIR spectra from non-extractable fractions of films $\mathrm{FE}_{1}$ (a) and $\mathrm{FE}_{2}$ (b), from epoxy sticking agent (c) and from the low molecular polyfunctional epoxy additive (d).

between spectra (a) and (b). Peaks at $1635 \mathrm{~cm}^{-1}$ and $1560 \mathrm{~cm}^{-1}$ have been attributed to the formation of secondary amide groups by Song et al. (22) as well as bands at $3300 \mathrm{~cm}^{-1}$ and $3100 \mathrm{~cm}^{-1}$. These authors pointed also out that peaks at $1560 \mathrm{~cm}^{-1}$ (asymmetric stretching) and $1400 \mathrm{~cm}^{-1}$ (symmetric stretching) may be due to carboxylate anions. They suggested that for low temperatures (below $120^{\circ} \mathrm{C}$ ), a reversible ionic reaction between amine functions of the aminosilane and carboxylic acid functions of the acetic acid used to adjust the $\mathrm{pH}$ of the sizing solution may occur, leading to salt (carboxylate anions) formation. Moreover, for higher temperatures (above $120^{\circ} \mathrm{C}$ ), nonreversible amide formation may occur though a deshydratation of the carboxylate anion. Furthermore, the peak located at $1635 \mathrm{~cm}^{-1}$ can be attributed to $\mathrm{C}=\mathrm{N}$ vibration of an imine group. According to Culler et al. (2), primary amines of silane may be oxidized in air to imine groups at temperatures above $120^{\circ} \mathrm{C}$. As sizing films are prepared after drying at $140^{\circ} \mathrm{C}$, this oxidation may occur. The differences in peak intensities at $1635 \mathrm{~cm}^{-1}$ and $1560 \mathrm{~cm}^{-1}$ may be related to a competition between (i) the amine/carboxylic acid reaction that occurs in both sizing systems and (ii) the amine/ epoxy (from the epoxy additive B) reaction, which occurs only in the sizing $\mathrm{E}_{2}$. This latter seems to predominate over the former.
FTIR absorption spectra from extractable fractions of films $\mathrm{FE}_{1}$ (a) and $\mathrm{FE}_{2}$ (b) are shown in Fig. 2 compared to individual components of the sizing formulations (spectra (c) and (d)). It can be seen that spectra (a), (b) and (c) are identical, indicating that the soluble part of both films corresponds to the epoxy sticking agent and not to the epoxy additive B (spectrum (d)). Spectra from extractable fractions in cyclohexane of glass fibers $F_{1}$ (a) and $F_{2}$ (b) are shown in Fig. 3. They are similar except for some differences at $2870 \mathrm{~cm}^{-1}$, $1093 \mathrm{~cm}^{-1}$ and $915 \mathrm{~cm}^{-1}$. These peaks can be attributed to the presence of some molecules of the epoxy additive B (see spectrum (d) in Fig. 2) in the soluble part of fiber $\mathrm{F}_{2}$. This result may suggest that some molecules (or the total amount) of the epoxy additive $\mathrm{B}$ do not react with aminosilane.

Further GPC measurements performed on cyclohexane extractable fractions and ethyl acetate extractable fractions of films $\mathrm{FE}_{1}$ and $\mathrm{FE}_{2}$ (Fig. 4) and of fibers $\mathrm{F}_{1}$ and $\mathrm{F}_{2}$ (Fig. 5) reveal more evidence supporting FTIR data and the idea that a given percent of the epoxy additive $\mathrm{B}$ has not reacted with the coupling agent. It can be seen that high molecular weight species, which correspond to the sticking agent $\mathrm{A}$, are present in both soluble fractions of films and that low molecular weight species, which correspond to the epoxy additive $\mathrm{B}$, are present only in the extractable part of the 


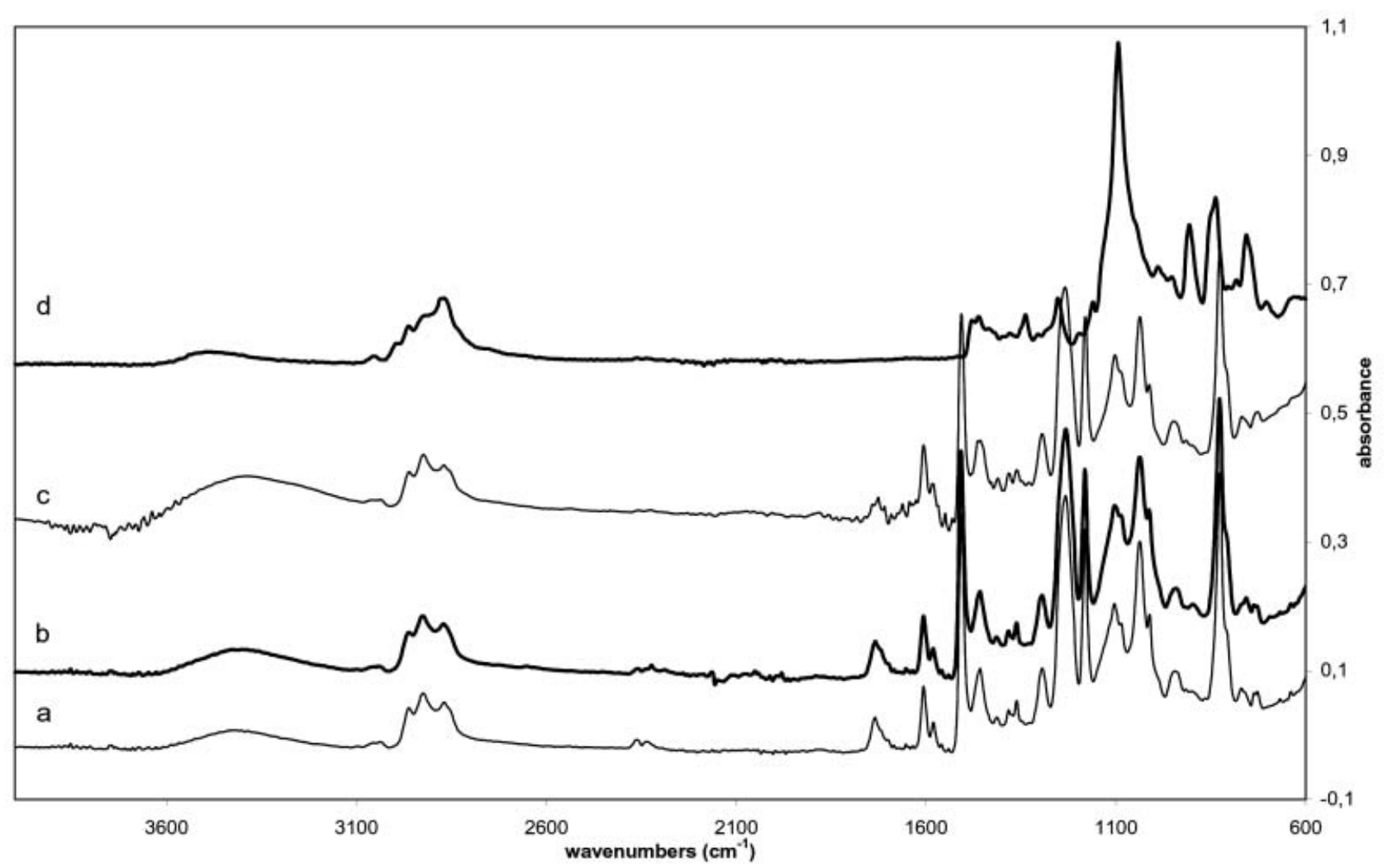

Fig. 2. FTIR spectra from extractable fractions of films $F E_{1}(a)$ and $F E_{2}$ (b), from epoxy sticking agent (c) and from the low molecular polyfunctional epoxy additive (d).



Fig. 3. FTIR spectra from extractable fractions in cyclohexane of glass fibers $F_{1}(a)$ and $F_{2}(b)$. 


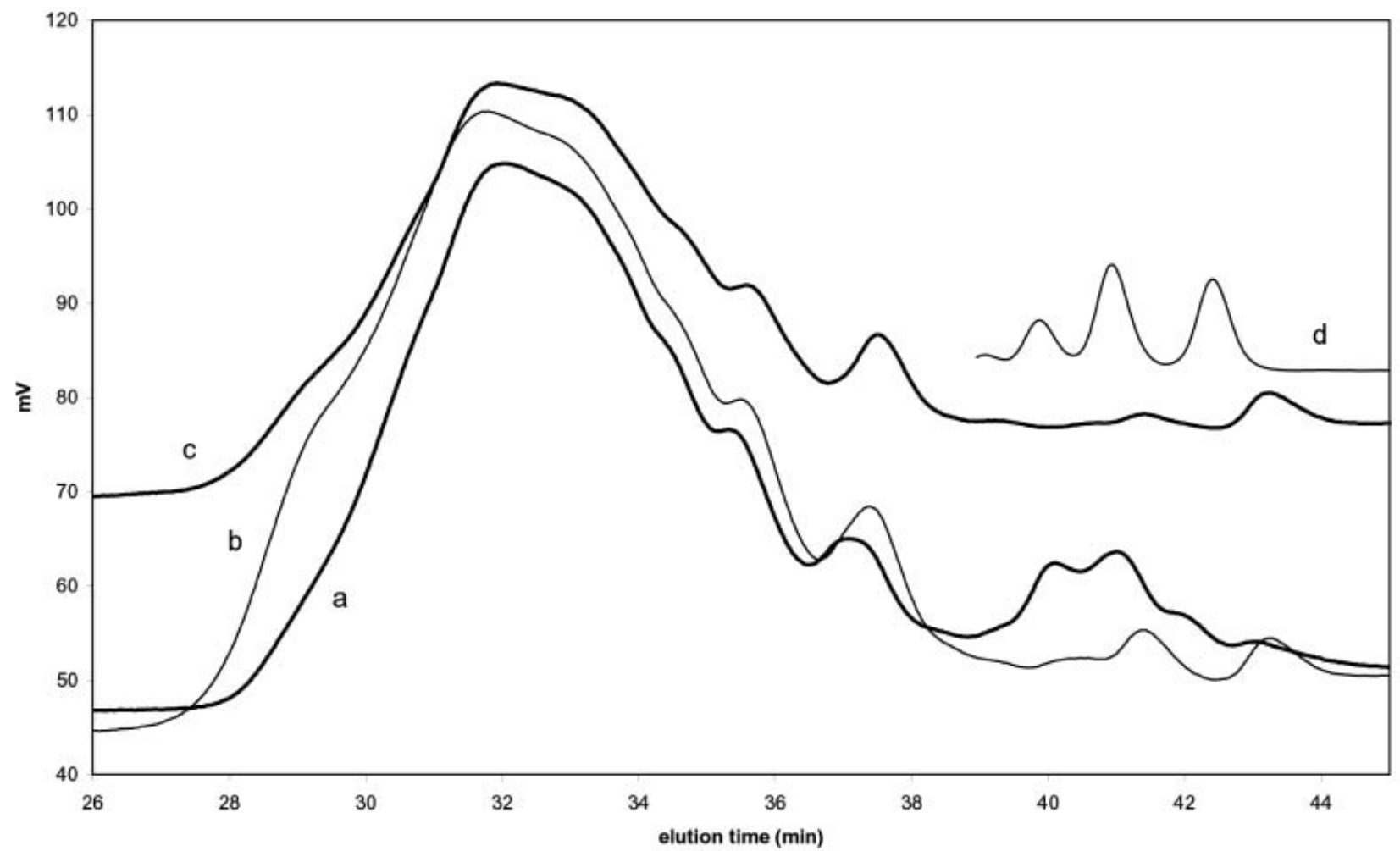

Fig. 4. GPC chromatograms from extractable fractions of films $F E_{1}$ (a) and $F E_{2}$ (b), from epoxy sticking agent (c) and from the low molecular polyfunctional epoxy additive (d).



Fig. 5. GPC chromatograms from cyclohexane extractable fractions of glass fibers $F_{1}(a)$ and $F_{2}(b)$ and from ethyl acetate extractable fractions of glass fibers $F_{1}(c)$ and $F_{2}(d)$. 
film $\mathrm{FE}_{2}$. The same results are obtained for glass fibers. In order to know if the aminosilane agent in the sizing could have partially reacted with the epoxy resin components, a sizing film $\mathrm{FE}_{2}$, was elaborated and then extracted. The formulation of the film $\mathrm{FE}_{2}$ is equivalent to those of the film $\mathrm{FE}_{2}$ without the coupling agent. The chromatograms of extractable parts of films $\mathrm{FE}_{2}$ and $\mathrm{FE}_{2}$ are compared in the low molecular weight region (Fig. 6) showing a decrease in peak intensities in presence of aminosilane, which is reproducible. This trend can be due to a consumption of some molecules of the epoxy additive $\mathrm{B}$ due to their partial reaction with aminosilane. Moreover, a simple calculation of the number of amine functions (coming from the aminosilane) compared to the number of epoxy functions (coming from the epoxy additive $\mathrm{B}$ ) indicates that the presence of the additive $\mathrm{B}$ in the extracts is related to an excess of the additive $B$ and not to a low amine/ epoxy reactivity rate.

From all these results a scheme of the different chemical reactions involved at the fiber surface for the sizing $\mathrm{E}_{2}$ can be proposed (Fig. 7). Several kinds of reactions may occur between the glass surface and the sizing solution during processing, which are: (i) formation of a polysiloxane network in the close neighborhood of the glass fiber, (ii) reaction between the amine end groups of this polysiloxane network and the acetic acid molecules to form amide functions, (iii) reaction between these amine end groups and the epoxy functions of the epoxy additive B. It was revealed that free molecules of epoxy sticking agent A and of epoxy additive $\mathrm{B}$ did not react with the aminosilane.

\section{Sizing/Matrix Interphase}

The identification of chemical reactions at the sizing/ matrix interphase was carried on by determining and analyzing, on one hand, the reactions involved in PBT/ epoxy compounds blends (PBT/A and PBT/B), and on the other hand the reactions involved in $\mathrm{PBT} /$ sizing film blends ( $\mathrm{PBT} / \mathrm{FE}_{1}$ and $\mathrm{PBT} / \mathrm{FE}_{2}$ ). Therefore, viscosity measurements, carboxyl end group titration, and viscoelastic and mechanical tests were performed. The purpose of this part of the study is to give evidence of the reactivity degree between each component of the different blends and of its influence on the microstructure and the mechanical behavior of the material.

Figure 8 shows the viscosity and the end group content versus the epoxy compound nature (pure PBT, $\mathrm{PBT} / \mathrm{A}$ and $\mathrm{PBT} / \mathrm{B}$ blends) and versus the processing steps (after single extrusion or after double extrusion or after double extrusion and injection). It can be observed that the end group content of pure PBT increases while the viscosity decreases during processing. According to the literature (23-26), this result should be related to degradation reactions causing the formation of short chain fragments with carboxylic and unsaturated ester end groups. Moreover, it seems that the degradation rate is greater after the first extrusion step. The same trend can be seen in the presence of the sticking agent A. On the other hand, an

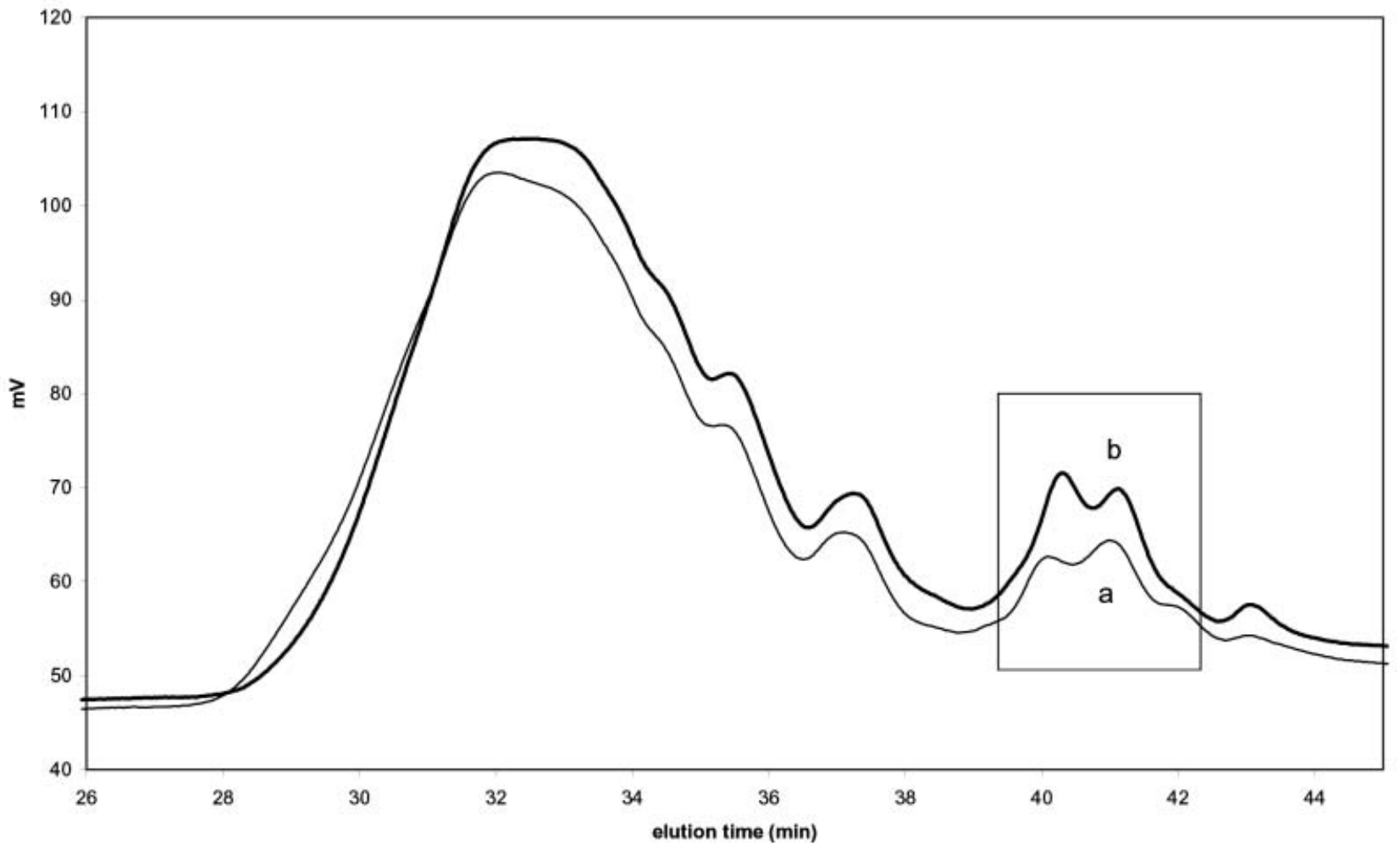

Fig. 6. GPC chromatograms from extractable fractions of films $\mathrm{FE}_{2}$ (a) and $\mathrm{FE}_{2}{ }_{2}$ (b). 


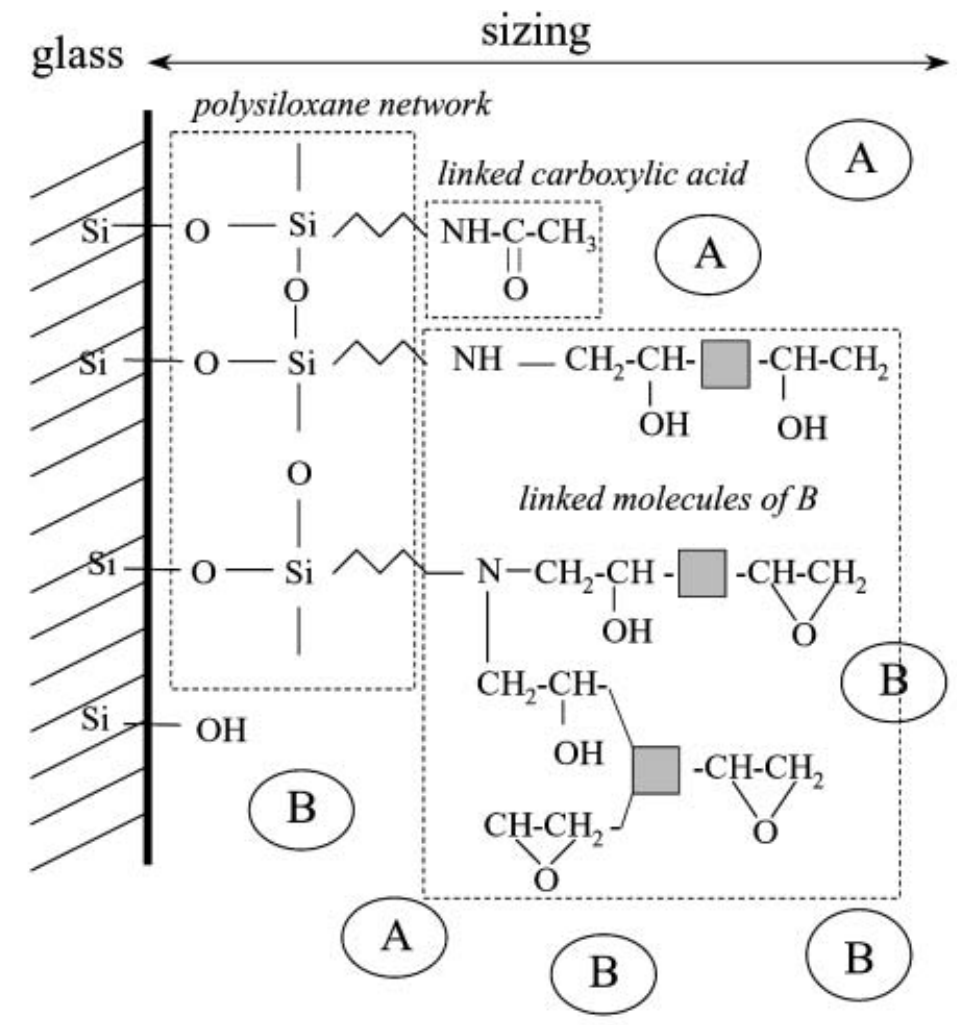

Fig. 7. Proposal for molecular arrangement at the fiber/sizing interphase: polysiloxane network, epoxy additive B, which has reacted with aminosilane, carboxylic acid, which has reacted with aminosilane to form amide functions, $\mathrm{B}$ free molecules of epoxy additive $B, A$ free molecules of epoxy sticking agent $A$.

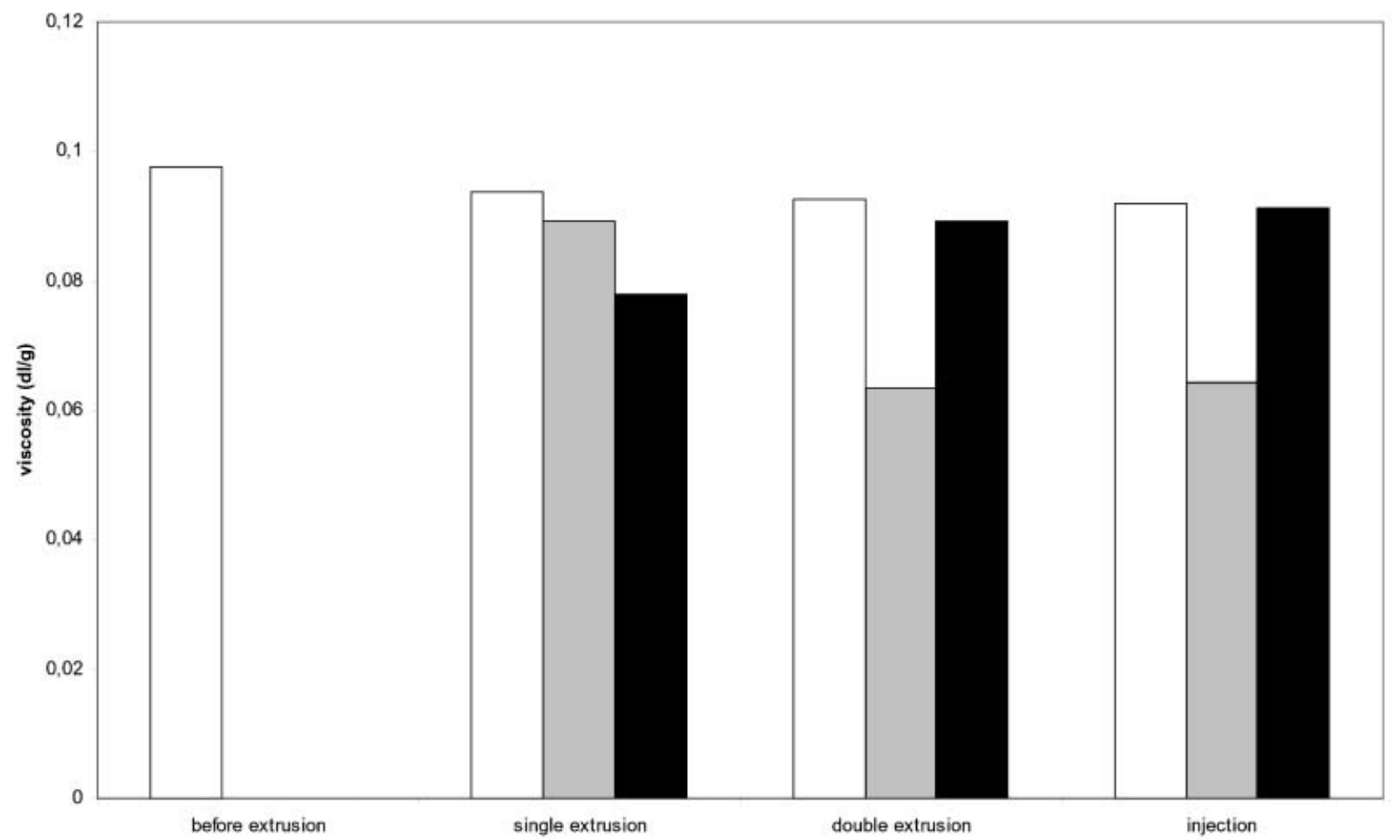

Fig. 8a. Viscosity as a function of processing steps (before extrusion, after single extrusion, after double extrusion and after double extrusion and injection molding) for PBT (white bars), PBT/A (gray bars) and PBT/B (black bars). 


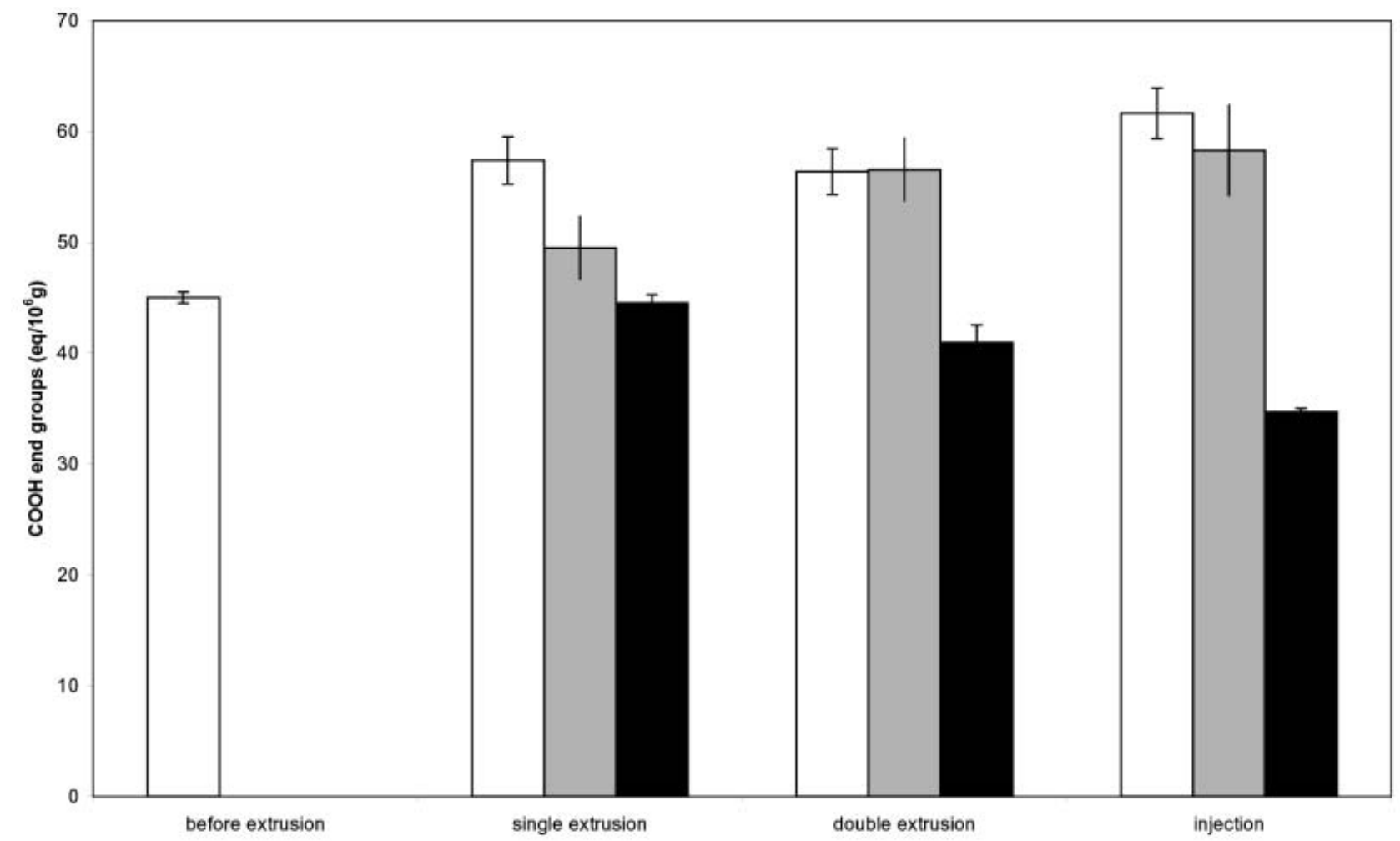

Fig. 8b. Carboxyl end content as a function of processing steps (before extrusion, after single extrusion, after double extrusion and after double extrusion and injection molding) for PBT (white bars), PBT/A (gray bars) and PBT/B (black bars).

inverse evolution was observed in the presence of the epoxy additive $\mathrm{B}$, indicating that carboxyl end groups of PBT may react with epoxy functions (which were present in excess) of the additive $B$ and that this reaction causes an overall increase in the viscosity even though the degradation reaction is still occurring. Nevertheless, it cannot be concluded from these data that no reaction occurs between carboxyl end groups of PBT and epoxy functions of the sticking agent A (the epoxy functions of A are in much lower concentration than those of $\mathrm{B})$. It can just be assumed that this latter reaction is limited and that the degradation reaction is predominant.

Figure 9 and Table 1 show, respectively, the tensile properties (Young's modulus and ultimate stress) and impact strength of $\mathrm{PBT} / \mathrm{A}$ and $\mathrm{PBT} / \mathrm{B}$ blends compared to pure PBT and the crystallinity ratios. A decrease in tensile stiffness and in crystallinity and an increase in impact strength in the presence of the epoxy additive $\mathrm{B}$ can be observed, indicating a plasticization process by the latter, which reduces the intermolecular interactions.

Figure 10 describes the viscoelastic behavior of pure PBT and both PBT/epoxy compounds (95/5 wt\%) blends. Only a few works have investigated the dynamic mechanical properties of PBT. Two mechanical relaxations have been pointed out by the authors (27, 28 ), the first located at about $-90^{\circ} \mathrm{C}$, which corresponds to the subglass $\beta$ transition, and the second located at about $+60^{\circ} \mathrm{C}$, which corresponds to the main $\alpha$ relaxation related to glass transition. Molecular motions connected to $\beta$ relaxation in PBT have been attributed $(29,30)$ to the superposition of two or three different elementary motions of methylene and ester groups of PBT chains. On the other hand, molecular motions related to $\alpha$ transition in PBT are due to cooperative motions of several monomer units of PBT chains. Therefore, the environment of the PBT chains should induce modifications in molecular motions and thus variations in the characteristics of $\alpha$ and $\beta$ relaxations.

For the PBT/A blend, we observed (i) no shift in temperature for both relaxations and no variations in crystallinity compared to PBT but (ii) a significant increase in peak magnitude for the $\alpha$ relaxation. In order to explain these results, it is necessary to determine how the PBT degradation reactions occurring during the process may influence the viscoelastic properties of PBT. As shown in Fig. 11, no significant variations in the characteristics of the $\alpha$ and $\beta$ relaxations during the process can be observed. Therefore, as the degradation process has no influence on both relaxations when this one remains limited, the observed increase in intensity of the $\alpha$ relaxation should correspond to the superposition of the $\alpha$ relaxation of PBT and of the main relaxation of the epoxy sticking agent A. Indeed, the glass transition temperatures of these last components are very close (about $67^{\circ} \mathrm{C}$ ). 


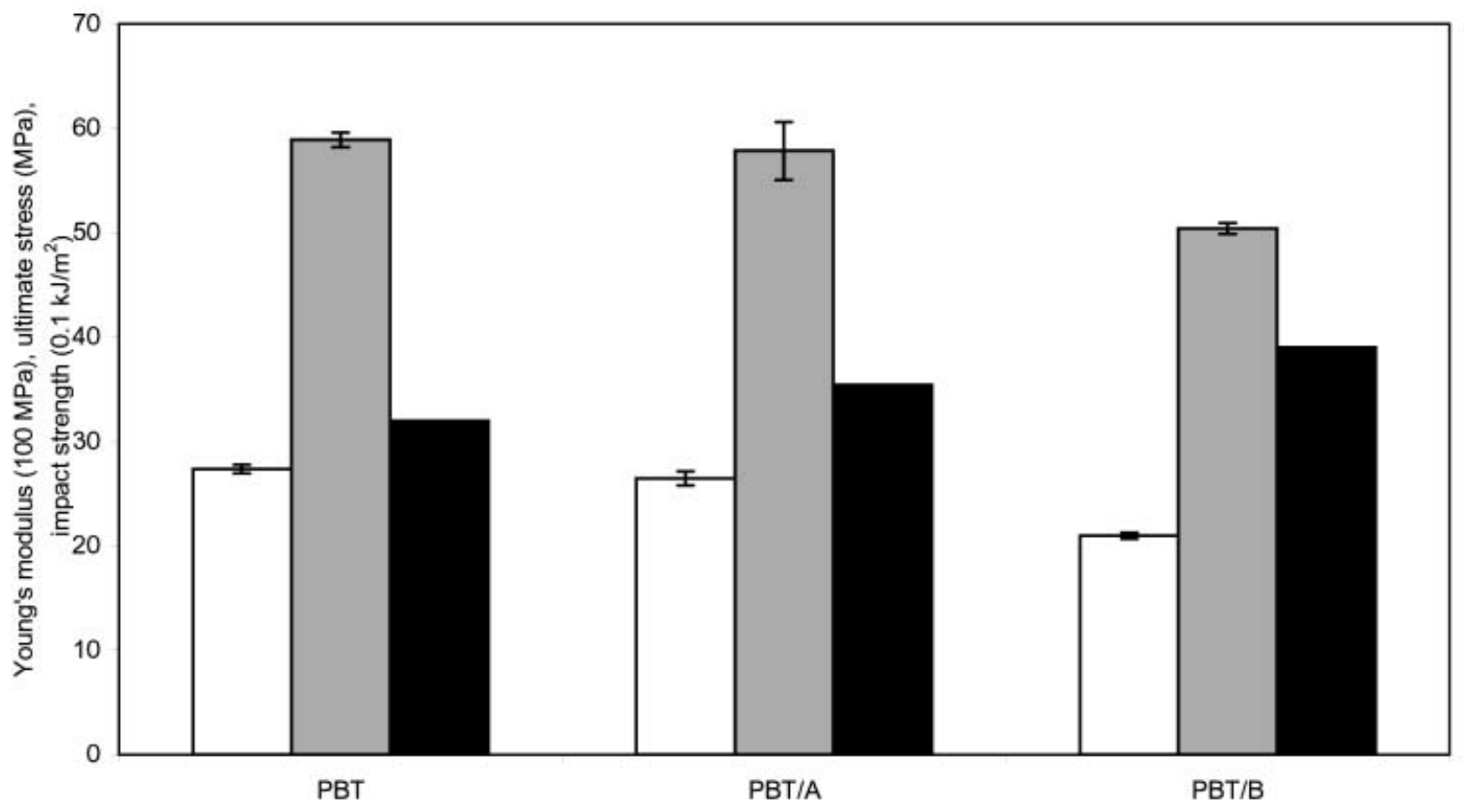

Fig. 9. Young's modulus (white bars; units: $100 \mathrm{MPa}$ ), ultimate tensile stress (gray bars; units: MPa) and impact strength (black bars; units: $0.1 \mathrm{~kJ} / \mathrm{m}^{2}$ ) of $P B T / A$ and $P B T / B$ blends compared to pure PBT.

For the PBT/B blend, previous viscosity and end group data have shown that molecules of the epoxy additive $\mathrm{B}$ should react with $\mathrm{COOH}$ end groups of PBT or with $\mathrm{COOH}$ groups formed by PBT chain scissions. Therefore, the decrease in $\beta$ and $\alpha$ peak intensities may indicate that these reactions affect the close surroundings of $\mathrm{COO}$ groups and induce a decrease in the motion. The shift towards lower temperatures for both relaxations $\left(-7^{\circ} \mathrm{C}\right.$ for $\alpha$ relaxation and $-4^{\circ} \mathrm{C}$ for $\beta$ relaxation) may be related to residual free molecules of the epoxy additive B confined inside macromolecular chains of PBT. The decrease in crystallinity and the lower amount of PBT for PBT/B blend (95 wt\%) compared to pure PBT may have no influence on viscoelastic properties.

The viscoelastic and thermal properties of PBT/sizing films $(80 / 20 \mathrm{wt} \%)$ blends are respectively presented in Fig. 10 and Table 1. The decrease in crystallinity and the lower amount of PBT in PBT/sizing film blends compared to PBT may induce a decrease in the magnitudes of the relaxation peaks. As results show that the viscoelastic properties remain unchanged whatever the sizing nature, it can be assumed that the chemical reactions occurring between the sizing films and the PBT matrix are similar.

\section{Chemical Description of the Interface Region in Composites}

Figure 12 gives the tensile and impact properties of composites reinforced by both kinds of fibers $\left(\mathrm{F}_{1}\right.$ and $\mathrm{F}_{2}$ ). No change in tensile strength is observed as the impact strength is increased in presence of the epoxy additive $\mathrm{B}$. This component may improve the adhesion quality at the fiber/matrix interphase and induce a lengthening of silane chains by a flexible aliphatic molecule therefore forming a softer interphase. From all these results the scheme proposed in Fig. 7 can be completed (Fig. 13).

\section{CONCLUSIONS}

The main feature of this study consists in the fact that the interface region has been divided into two separate regions, the fiber/sizing interphase and the sizing/matrix interphase. Results have shown that adhesion improvement between the fiber and the matrix is due to the presence in the sizing of a short chain coupling agent and of a polyfunctional additive, which may react both with the coupling agent and with the matrix. According to the nature of this additive, it may be possible to soften the interphase and

Table 1. Thermal Properties (Melting Enthalpy $\Delta H_{m}$ and Melting Temperature $T_{m}$ ) of PBT/Epoxy Compound Blends and PBT/Sizing Film Blends Compared to Pure PBT.

\begin{tabular}{lccccc}
\hline & PBT & PBT/FE $_{\mathbf{1}}$ & PBT/FE $_{\mathbf{2}}$ & PBT/A & PBT/B \\
\hline$\Delta \mathrm{H}_{\mathrm{m}}(\mathrm{J} / \mathrm{g})$ & $-55.3 \pm 1.1$ & $-61.0 \pm 0.1$ & $-64.3 \pm 0.5$ & $-54.3 \pm 0.4$ & $-47.5 \pm 0.7$ \\
$\mathrm{~T}_{\mathrm{m}}\left({ }^{\circ} \mathrm{C}\right)$ & $227.7 \pm 0.1$ & $228.2 \pm 0.6$ & $228.0 \pm 0.5$ & $229.7 \pm 0.6$ & $227.1 \pm 0.3$ \\
\hline
\end{tabular}




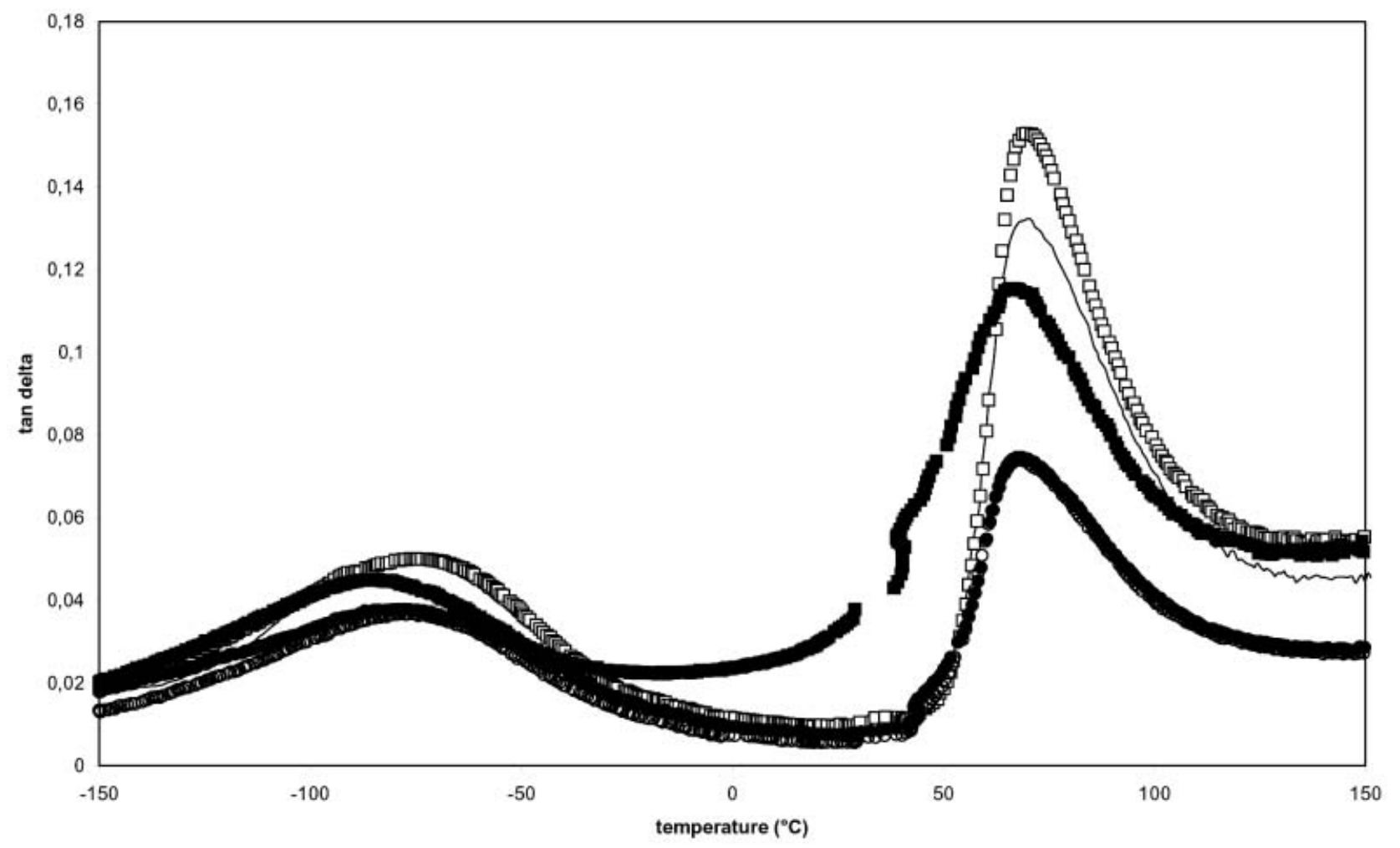

Fig. 10. Viscoelastic properties of PBT/A blend (white squares), PBT/B (black squares) blend, PBT/FE $E_{1}$ blend (white circles) and $\mathrm{PBT} / \mathrm{FE}_{2}$ blend (black circles) compared to pure PBT (full line).

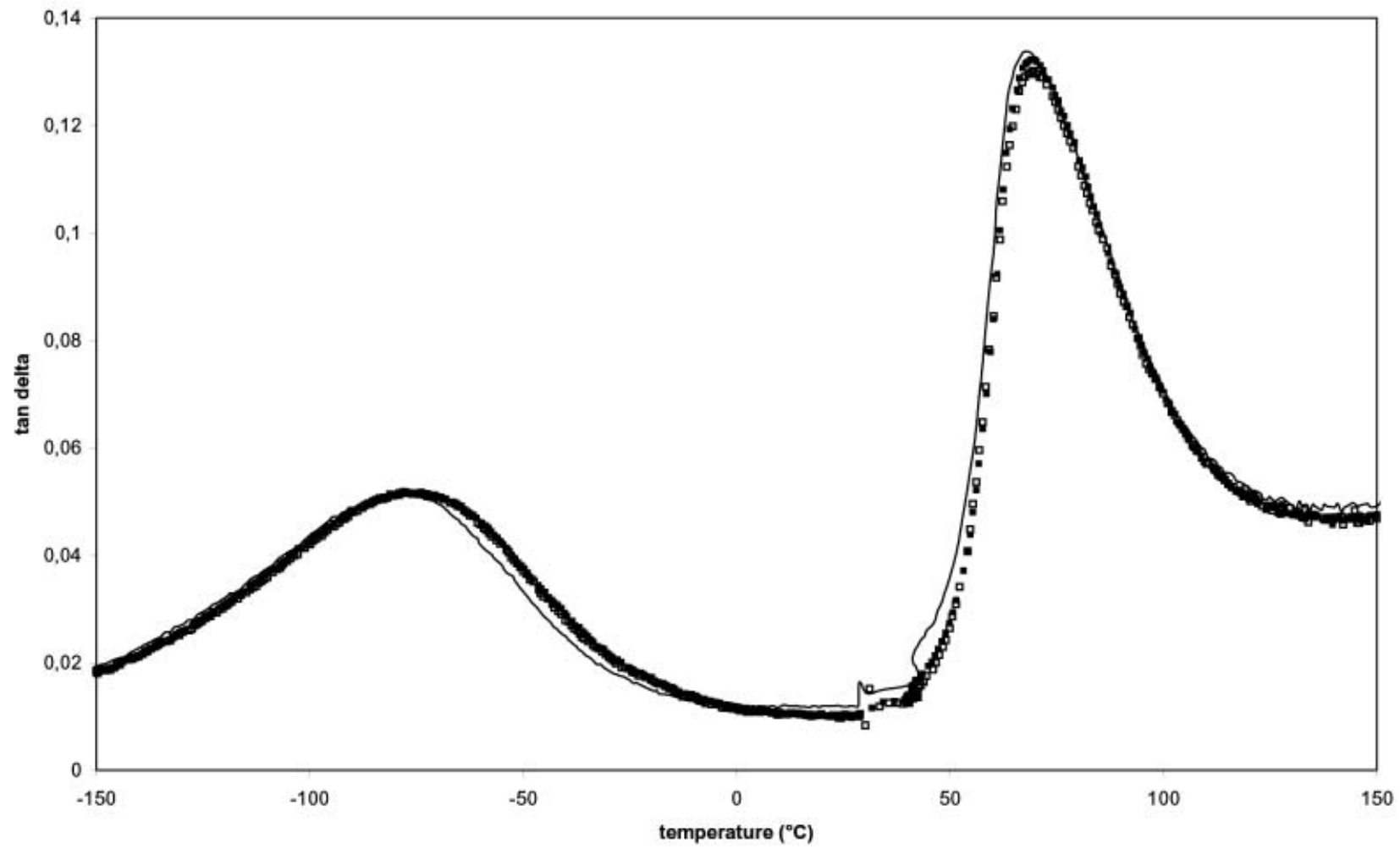

Fig. 11. Viscoelastic properties of pure PBT versus the processing steps: before extrusion (full line), after single extrusion and injection molding (black squares) and after double extrusion and injection molding (white squares). 


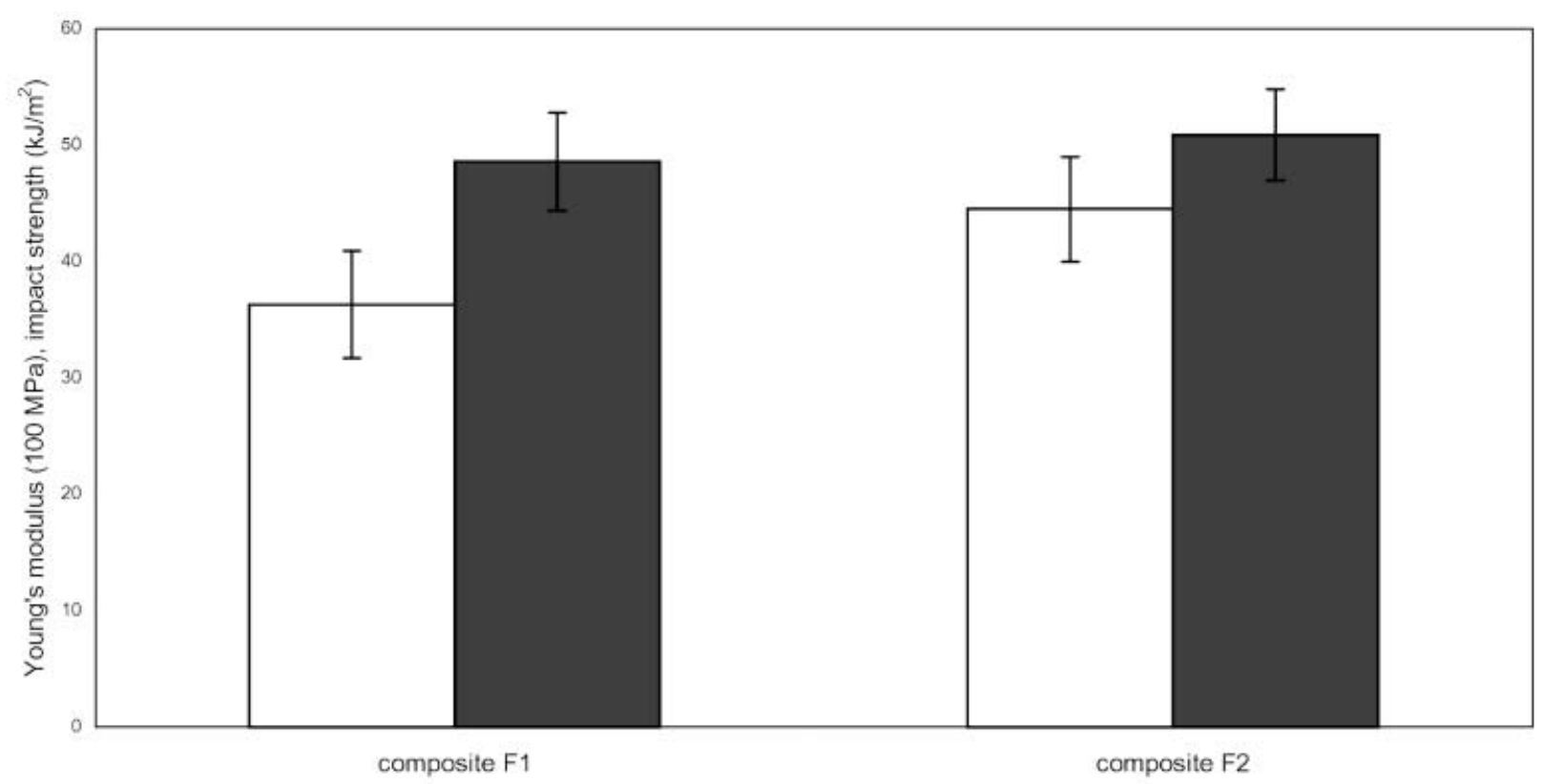

Fig. 12. Young's modulus (black bars; units: $100 \mathrm{MPa}$ ) and impact strength (white bars; units: $k J / \mathrm{m}^{2}$ ) of composites $F_{1}$ and $F_{2}$.

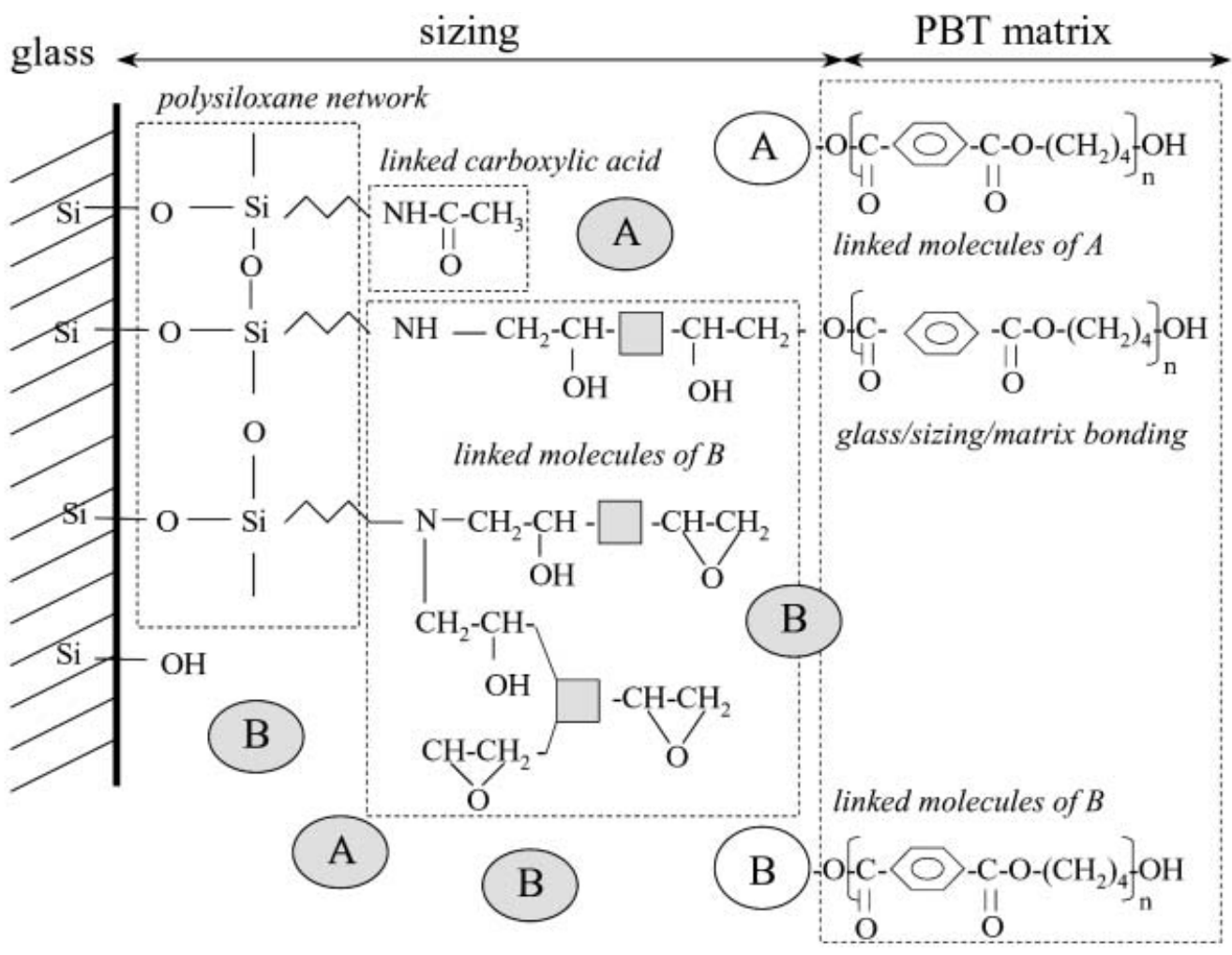

Fig. 13. Proposal for molecular arrangement at the fiber/sizing and sizing/matrix interphases: polysiloxane network, epoxy additive $B$, which has reacted with aminosilane, carboxylic acid, which has reacted with aminosilane to form amide functions, PBT matrix, which has reacted either with sticking agent $A$ or epoxy additive $B, B$ free molecules of epoxy additive $B, A$ free molecules of epoxy sticking agent $A$. 
then to increase the impact strength of the composite. Moreover, this study has shown that in the case of PBT/glass fiber composites, a better fiber/matrix adhesion may occur when the ratio between reactive functions of the coupling agent (amine groups) and reactive functions of the sticking agents (epoxy groups of $\mathrm{A}$ and $\mathrm{B}$ ) is lower than unity so that free functions of the sticking agents may react with the matrix chains and create an interpenetrated and a crosslinked network of macromolecular chains.

\section{REFERENCES}

1. L. T. Drzal, M. J. Rich, and P. F. Lloyd, J. Adhesion, 16 1 (1983).

2. S. R. Culler, H. Ishida, and J. L. Koenig, Polym. Composites, 7, 231 (1986).

3. K. P. Hoh, H. Ishida, and J. L. Koenig, Polym. Composites, 9, 151 (1988)

4. T. E. Gentle, R. G. Schmidt, B. M. Naasz, A. J. Gellman, and T. M. Gentle, J. Adhesion Sci. Technol., 6, 307 (1992).

5. Y. T. Liao, Polym. Composites, 10, 424 (1989).

6. N. Nishiyama, R. Shick, and H. J. Ishida, Colloid Interf. Sci., 143, 146 (1991).

7. J. L. Koenig and H. Emadipour, Polym. Composites, 6 , 142 (1985).

8. E. J. Berger and Y. Eckstein, Adhesive Joints, Plenum Publishing Corporation, 51-65 (1984).

9. C. Y. Yue and M. Y. Quek, J. Mater. Sci., 29, 2487 (1994).
10. J. L. Thomason, Composites, 26, 487 (1995).

11. P. S. Chua, Polym. Composites, 8, 308 (1987).

12. A. Bergeret and N. Alberola, Polymer, 37, 2759 (1996).

13. J. Chauchard, B. Chabert, P. Jeanne, and G. J. Nemoz, Chimie Physique, 84 (1987).

14. K. E. Reed, Polym. Composites, 1, 44 (1980).

15. V. F. Babich and Y. S. Lipatov, J. Appl. Polym. Sci., 27, 53 (1982).

16. J. F. Gerard, Polym. Eng. Sci., 28, 568 (1988).

17. J. L. Thomason, Polym. Composites, 11, 105 (1990).

18. C. Gauthier, L. Caramaro, and J. J. Chauchard, C. R. Acad. Sci., Paris, T313, II, 891 (1991).

19. M. P. Bozec, PhD Thesis, Univ. Montpellier II, Montpellier, France (1999)

20. H. A. Pohl, Anal. Chem., 26, 1614 (1954).

21. C. C. Huang and F. C. Chang, Polymer, 38, 2165 (1997).

22. Z. Song and W. E. Baker, J. Polym. Sci. Part A: Polym. Chem., 30, 1589 (1992).

23. I. Luderwald, Dev. Polym. Deg., 2, 77 (1979).

24. R. M. Lum, J. Polym. Sci. Part A: Polym. Chem., 17, 203 (1979).

25. V. Passalacqua, F. Pilati, V. Zamboni, B. Fortunato, and P. Manaresi, Polymer, 17, 1044 (1977).

26. E. P. Goodings, Monogr. Soc. Chem. Ind., 13, 211 (1961).

27. I. I. Perepechko, V. A. Danilov, V. V. Nizhegorodov, N. P. Bessonovo, and E. V. Konyukhova, Polym. Sci., 35, 193 (1993).

28. O. Beaudoin, A. Bergeret, J. C. Quantin, and A. Crespy, Composite Interfaces, 5, 543 (1998).

29. G. Farrow, J. McIntosh, and I. M. Ward, Makromol. Chem., 38, 147 (1960).

30. K. H. Illers and H. J. Breuer, Colloid Sci., 18, 1 (1963). 